\title{
Post-translational Modification of Pregnane X Receptor
}

\author{
Jeff L. Staudinger ${ }^{a},{ }^{*}$, Chenshu $\mathrm{Xu}^{\mathrm{a}}$, Arunima Biswas ${ }^{\mathrm{b}}$, and Sridhar Mani ${ }^{\mathrm{b}}$ \\ a Pharmacology and Toxicology, University of Kansas \\ ${ }^{b}$ Department of Medicine, Albert Einstein College of Medicine
}

\begin{abstract}
Pregnane $x$ receptor (PXR, NR1I2) was originally characterized as a broad spectrum enterohepatic xenobiotic 'sensor' and master-regulator of drug inducible gene expression. A compelling description of ligand-mediated gene activation has been unveiled in the last decade that firmly establishes this receptor's central role in the metabolism and transport of xenobiotics in mammals. Interestingly, pharmacotherapy with potent PXR ligands produces several profound side effects including decreased capacities for gluconeogenesis, lipid metabolism, and inflammation; likely due to PXR-mediated repression of gene expression programs underlying these pivotal physiological functions. An integrated model is emerging that reveals a sophisticated interplay between ligand binding and the ubiquitylation, phosphorylation, SUMOylation, and acetylation status of this important nuclear receptor protein. These discoveries point to a key role for the posttranslational modification of PXR in the selective suppression of gene expression, and open the door to the study of completely new modes of regulation of the biological activity of PXR.
\end{abstract}

\section{Keywords}

Pregnane x receptor; Post-translational modification

\section{Introduction}

Pregnane $x$ receptor (PXR, NR1I2) was originally identified on the basis of its sequence homology with other nuclear receptor (NR) proteins in the expressed sequence tag database. The full-length mouse PXR cDNA was characterized in 1998 using the expressed sequence tag to screen a mouse liver cDNA library, and the receptor was named PXR based on its activation by pregnane (21-carbon) steroids [1]. Shortly after its discovery, PXR was classified as a broad specificity receptor that is activated by a wide variety of drugs and xenobiotic compounds as a heterodimer with RXR $\alpha$. Upon ligand binding the PXR-RXR heterodimer binds to multiple sites on the cytochrome P450 3A (CYP3A) promoter and activates gene expression and provides the molecular basis for the induction of $C Y P 3 A$ gene expression by xenobiotics [1-3].

(C) 2011 Elsevier Ltd. All rights reserved.

*Corresponding author: Pharmacology and Toxicology, University of Kansas, 1251 Wescoe Hall Dr., 5038a Malott Hall, Lawrence, KA 66045, USA. Tel.: 785-864-3951; fax: 785-864-5219, stauding@ku.edu.

Publisher's Disclaimer: This is a PDF file of an unedited manuscript that has been accepted for publication. As a service to our customers we are providing this early version of the manuscript. The manuscript will undergo copyediting, typesetting, and review of the resulting proof before it is published in its final citable form. Please note that during the production process errors may be discovered which could affect the content, and all legal disclaimers that apply to the journal pertain. 


\section{PXR Ligands}

Numerous ligands for PXR have been identified across various species, and it is now well accepted that a species-specific PXR-activation profile exists. For example, mouse and rat PXR are activated by the CYP3A inducer pregnenalone $16 \alpha$-carbonitrile (PCN), whereas PCN has little effect on human and rabbit PXR. On the other hand, rifampicin (Rif) activates human and rabbit PXR but has virtually no effect on the mouse and rat receptors [3-6]. In fact, PXR is activated by a broad range of lipophilic compounds including a myriad of synthetic and endogenous steroids, certain bile acids, and a variety of drugs and plant products. In contrast to the classic steroid hormone receptors, high-affinity (sub-nanomolar) ligands for PXR have not been discovered. For example, the lowest $\mathrm{EC}_{50}$ values of steroids that activate PXR are low-micromolar, generally two to three orders of magnitude higher than concentrations found in circulating plasma $[5,6]$.

\section{PXR-target Genes}

PXR ligands have been shown to stimulate expression of genes that encode enzymes involved in the oxidation (phase I), conjugation (phase II) and transport (phase III) of xenobiotics. The first genes shown to be directly regulated by ligand-mediated PXR activation were CYP3A family members in both mouse and human liver and intestine $[1,3]$. Additional phase I drug metabolism gene products regulated by PXR include numerous cytochrome P450s, aldehyde dehydrogenases, alcohol dehydrogenases, carboxylesterases, and several enzymes involved in heme production and support of the CYP cycle such as aminolevulonic acid synthase and P450 oxidoreductase [7, 8]. Phase II drug metabolism gene products regulated by PXR activation include UDP-glucuronosyl-transferases, sulfotransferases and glutathione S-transferases [8-13]. Finally, phase III drug transporters gene products regulated by PXR include numerous ATP-binding cassette membrane pumps of the multidrug resistant family and organic anion transporting protein 1A4 in rodents [14$16]$.

\section{Negative Physiological Functions of PXR}

While the molecular basis for ligand-mediated PXR gene activation programs controlling drug metabolism and drug transport activity is relatively well described, much less is known about the molecular mechanisms governing the observed ligand-dependent repressor function of the PXR protein. Recent research efforts indicate that ligand-mediated activation of PXR negatively regulates several key biochemical functions in liver and intestine including the synthesis of glucose, ketone bodies, $\beta$-oxidation and transport of lipids, as well as inflammatory processes (Figure 1). The general mechanism for drug-mediated repression of these important physiological functions appears to involve protein-protein interactions between liganded-PXR and the transcription factors and accessory proteins required for driving full-activation of respective programs of gene expression. The molecular basis for reciprocity between these biochemical pathways is currently the focus of several research groups, and the biochemical details are currently emerging.

\section{Glucose Homeostasis}

Glucose production by liver is tightly controlled by the insulin and glucagon signaling pathways. These counter-regulatory signaling pathways play a critical role in survival during fasting and starvation by regulating the transcription of key target genes comprising the gluconeogenic gene expression program including glucose-6-phosphatase (G6Pase) and phosphoenolpyruvate carboxykinase $(P E P C K)$. Glucagon increases glucose production by up-regulating the transcription of key genes that encode the rate-limiting enzymes in the gluconeogenic pathway, whereas insulin signaling rapidly suppresses the expression of the 
genes encoding these tightly regulated enzymes. The CREB protein is a cellular transcription factor that binds to certain DNA sequences called cyclic AMP response elements (CREs), thereby increasing the transcription of downstream genes. Glucagon stimulates cyclic AMP-dependent protein kinase (PKA) that phosphorylates CREB. PKAphosphorylated CREB binds to CREs and activates the transcription of genes that contain CREs in their promoter such as G6Pase and PEPCK1. Phosphorylated CREB then transactivates the expression of G6Pase and PEPCK.

Previous observations have revealed functional links between glucose metabolism and PXRmediated signaling pathways. For example, it is known that PXR ligands repress expression of G6Pase and PEPCK [17-19]. Treatment with the potent rodent PXR activator PCN decreased blood glucose levels in fasting wild-type mice, but not in PXR-null mice [19]. Moreover, the genes that encode G6Pase and PEPCK are decreased in transgenic mice that express a constitutively activated form of human PXR [20]. These data suggest that sustained PXR activation actively represses the gluconeogenic pathway through interference with or sequestration of transcription factors and protein cofactors that are involved in transcriptional regulation.

Forkhead box protein O1 (FOXO1) belongs to the forkhead family of transcription factors which are characterized by a distinct fork head domain. In hepatic cells, a dephosphorylated form of FOXO1 drives the transcription of G6Pase and PEPCK and its presence in the nucleus is required for full activation of the gluconeogenic program of gene expression. Insulin signaling activates the phosphatidylinositol 3-kinase-Akt pathway to phosphorylate FOXO1, excluding it from the nucleus and resulting in the insulin-dependent repression of G6Pase and PEPCK [21, 22]. Interestingly, FOXO1 has been shown to interact with several NR proteins to function as either a transcriptional corepressor or coactivator protein [23, 24]. Moreover, the FOXO1 protein was found to function as a coactivator of PXR-mediated gene activation. In contrast, ligand-mediated activation of PXR suppressed FOXO1

transcriptional activity by preventing binding to its response element in target genes such as G6Pase and PEPCK [25].

It has also been proposed that PXR inhibits the expression of gluconeogenic enzymes by interfering with CREB signaling. PXR activation results in the repression of CREBmediated activation of the G6Pase promoter in both mice and in a human hepatocarcinoma cell line. This apparently occurs through the binding of liganded-PXR protein directly to CREB, which thereby prevents CREB interaction with the CRE on the G6Pase promoter [19].

The NR coactivator protein peroxisome proliferator-activated receptor gamma coactivator 1alpha (PGC-1 $\alpha$ ) is induced by glucagon and coactivates hepatocytes nuclear factor $4 \alpha$ (HNF-4 $\alpha$ )-mediated transcription of G6Pase and PEPCK. Ligand-activated PXR dissociates PGC- $1 \alpha$ from HNF-4 $\alpha$ through a direct competition/squelching mechanism, thereby repressing the transcription of PEPCK and G6Pase [18]. Since PGC-1 $\alpha$ is also a co-factor for CREB- and FOXO1-mediated expression of gluconeogenic-target genes, a similar mechanism implicating sequestration of PGC- $1 \alpha$ from these two transcription factors by PXR is likely to be responsible for drug-mediated repression of gluconeogenesis. Hence, the underlying molecular mechanism of PXR-mediated repression of glucose production appears to be the direct binding of PXR to transcription factors and accessory proteins that activate gene expression programs critical for the gluconeogenisis such as FOXO1, CREB, $\mathrm{HNF} 4 \alpha$, and PGC- $1 \alpha$. 


\section{Lipid Metabolism and Ketogenesis}

It is well known that treatment with drugs, now classified as PXR activators, affect lipid metabolism in patients. For example, treatment with Rif or carbamazepine can induce hepatic steatosis, characterized by the abnormal accumulation of triglycerides in liver [26, 27]. It appears that drug- and lipid-metabolism are interconnected through a complex network of transcriptional regulators that include PXR. The role for PXR in the development of hepatic steatosis raises some concern regarding the development and safety of drugs that are potent PXR ligands. Overall, the role of PXR in lipid metabolism and steatosis warrants further investigation, however, recent studies indicate a clear role for this receptor in the regulation of hepatic lipid metabolism.

When blood glucose is low, the liver metabolizes fatty acids via $\beta$-oxidation to provide ketone bodies to extra-hepatic tissues. Forkhead box A2 (FOXA2) has been shown to positively regulate this process by controlling the transcription of target genes including carnitine palmitoyltransferase 1A and 3-hydroxy-3-methylglutaryl-CoA synthase 2 [28, 29]. It has been suggested that ligand-activated PXR represses hepatic energy metabolism by decreasing both $\beta$-oxidation and ketogenesis. Treatment with PCN down-regulates the expression of genes encoding carnitine palmitoyltransferase 1A and 3-hydroxy-3methylglutaryl-CoA synthase 2 in wild type, but not in PXR-null mice. It was further shown that activated PXR and FOXA2 physically interact through their ligand- and DNA-binding domains, respectively. This interaction prevents FOXA2 from binding to its response elements and leads to the repression of carnitine palmitoyltransferase 1A and 3-hydroxy-3methylglutaryl-CoA synthase 2 [30]. In addition, it has been shown that HNF-4 $\alpha$ directly regulates expression of carnitine palmitoyltransferase 1A [31]. It has been demonstrated that PXR interferes with HNF- $4 \alpha$ signaling by targeting PGC- $1 \alpha$ and producing a squelching effect [18]. Since HNF-4 $\alpha$ and PGC- $1 \alpha$ are jointly involved in the regulation of carnitine palmitoyltransferase 1A it is likely that crosstalk with ligand-activated sequestering by PXR applies to this gene promoter as well through its interaction with FOXA2.

\section{Inflammatory Response}

Exposure to xenobiotics can impair immune function. In fact, it is a long-standing observation that Rif tends to suppress immunological responses in liver cells [32-34]. Recent publications have demonstrated a mutual inhibition between PXR and the inflammatory mediator nuclear transcription factor kappa B (NF-kB), thus providing a potential molecular mechanism that links xenobiotic metabolism and inflammation [35, 36]. Activation of PXR by Rif suppresses the expression of typical NF- $\kappa \mathrm{B}$ target-genes such as cyclooxygenase-2, tumor necrosis factor $\alpha(T N F \alpha)$, intercellular adhesion molecule-1 and several interleukins [36]. Conversely, NF- $\mathrm{kB}$ activation by lipopolysaccharide and TNF $\alpha$ results in the suppression of CYP3A activity through interactions of NF- $\kappa B$ with the PXRretinoid-x-receptor complex [37]. Furthermore, hepatocytes derived from PXR-null mice have elevated NF- $\mathrm{KB}$ target-gene expression compared to hepatocytes from wild-type mice. The PXR-null mice also exhibit heightened signs of inflammation in their liver and small bowel $[36,38]$. This could be due to the loss of negative regulation of NF- $\mathrm{KB}$ activity following PXR activation, or is perhaps due to inadequate clearance of toxic substances in the absence of PXR.

Several fundamental questions remain regarding the molecular mechanisms of PXRmediated gene repression. For instance, (1) does the selective interaction of liganded-PXR with transcription factors and accessory proteins involve post-translational modification of the PXR protein? (2) Is the selective repression of specific programs of gene expression dependent upon modification-mediated conformational change of the PXR protein? (3) How do ubiquitination, phosphorylation, SUMOylation, and acetylation of PXR integrate to affect 
PXR-target gene activation and subsequent biochemical functions in the entero-hepatic system? It is therefore important to briefly review the direct evidence for post-translational modification of PXR, and also discuss the likely interplay of ligand binding with the ubiquitylation, phosphorylation, SUMOylation, and acetylation status of PXR.

\section{Ubiquitination of PXR}

While degradation is known to play an important role in NR function [39], relatively little is known about the degradation of PXR. PXR was found to interact with suppressor for gal-1, a key component of the $26 \mathrm{~S}$ proteasome complex, in the presence of progesterone but not in the presence of endocrine disrupting chemicals [40]. A follow up study confirmed that PXR is differentially degraded in response to progesterone when compared with endocrine disrupting chemicals [41]. This finding suggests that proteasomal-mediated PXR degradation may be differentially affected by various PXR agonists. The extent to which ubiquitination and/or degradation of PXR protein affects glucose, lipid, ketone body, and inflammatory status in mammals is worthy of further investigation.

Our laboratory has recently developed a cell-based over-expression and western blot experimental approach for direct detection of ubiquitinated PXR (Figure 2A). As expected, detection of ubiquitinated PXR protein is dramatically increased in response to pharmacological inhibition of 26S proteasome activity with MG132 (Figure 2B, lane 4). Interestingly, forced activation of the PKA signaling pathway selectively increases the ubiquitination of PXR (Figure 2B, lane 6, note the asterisks). Notably, pharmacological inhibition of the proteosomal degradation pathway abolishes PXR transactivation of the CYP3A4 promoter in reporter gene transfected CV-1 cells (Figure 2C). This is consistent with an ubiquitin-dependent promoter clearance mechanism, and is highly reminiscent of recent reports detailing similar modes of regulation of NR proteins peroxisome proliferatoractivated receptor gamma (PPAR $\gamma, \mathrm{NR} 1 \mathrm{C} 3)$ and liver-x receptor alpha/beta (LXR $\alpha / \beta$, NR1H3/NR1H2) [42-44]. The interaction between PXR and the ubiquitin signaling pathway appears to be relatively complex and warrants further investigation.

\section{Phosphorylation of PXR}

Protein phosphorylation plays an important role in the regulation of PXR function [45]. Treatment of mouse hepatocytes with the cyclic AMP-dependent protein kinase (PKA) activator 8-Bromo-cyclic AMP increased the induction of Cyp3a11 by the PXR agonist taxol and enhanced the binding of mouse PXR to the transcriptional coactivator proteins Steroid Receptor Coactivator-1 and Peroxisome Proliferator-activated Receptor (PPAR)binding Protein. Furthermore, kinase assays show that PXR can serve as a substrate for catalytically active PKA in vitro, suggesting one potential mechanism for PKA-mediated modulation of CYP3A gene expression [46]. Additionally, there appears to be significant species differences in the effect of kinase signaling pathways. For example, while PKA activation increases PXR activity in mouse hepatocytes, it serves as a repressive signal in both human and rat hepatocytes. Similar to the PXR-ligand response, this suggests a speciesspecific effect for the modulation of drug-inducible CYP3A gene expression by PKA signaling [47].

Activation of protein kinase $\mathrm{C}$ signaling by phorbol myristate acetate repressed PXR activity in reporter gene assays and in hepatocytes by increasing the strength of interaction between PXR and the nuclear receptor corepressor (NCoR) protein, and by abolishing the liganddependent interaction between PXR and Steroid Receptor Coactivator-1. Interestingly, the protein phosphatase PP1/2A inhibitor okadaic acid strongly represses PXR-dependent transactivation [48]. In addition, cyclin-dependent kinase 2 (Cdk2) attenuated the activation of CYP3A4 gene expression. PXR is a suitable substrate for the Cdk2 enzyme in vitro, and a 
phosphomimetic mutation at a putative Cdk2 phosphorylation site at (S350D) impaired the function of human PXR, whereas a phosphorylation-deficient mutation (S350A) conferred resistance to the repressive effects of Cdk2 on a reporter gene in HepG2 cells [49]. The results of these studies confirm that the activity of PXR is modulated by changes in its overall phosphorylation status. Determining whether phosphorylation of PXR at specific sites influences the integration between cell-signaling pathways and PXR-mediated repression remains an open and important question for future research.

\section{SUMOylation of PXR}

Long-term treatment of patients with Rif inhibits the inflammatory-response in liver [ 34 , 37]. Though the molecular basis for this phenomenon has remained obscure, it was recently predicted that it should involve SUMOylation of PXR in intestine and liver [50]. We have demonstrated that activation of the inflammatory response in hepatocytes strongly modulates the SUMOylation status of ligand-bound PXR [38]. The SUMOylated PXR protein contains SUMO2/3 chains and feedback represses the immune response in hepatocytes and likely in intestinal tissue as well. Future studies of SUMOylation are expected to provide a novel paradigm that uniquely defines the molecular basis of the interface between PXR-mediated gene activation, drug metabolism and inflammation in intestine and liver tissue.

A non-biased approach for identification of the sites and molecular mechanisms of PXR SUMOylation is badly needed. We have therefore designed a strategy that is based upon a very recent report in the literature [51]. Our experimental approach utilizes a forced overexpression cell-based assay and is depicted in figure 3A. A novel SUMO expression construct based on the amino acid sequence of SUMO-3 encodes a protein which we have termed SUMO-X, and the amino acid substitutions are depicted in figure 3B.

The SUMO-X protein incorporates several key features to allow non-biased enrichment and identification of SUMOylated PXR peptides produced in vitro, in cultured cells, or in live animals. This novel strategy creates an identifiable diglycil lysine signature tag on SUMOylated PXR peptides that will be detected by mass spectrometry. The key amino acid substitutions in SUMO-X are depicted in red lettering in Figure 3C. The SUMO-X contains an N-terminal 6X-histidine-tag that allows enrichment of total SUMOylated substrates from an in vitro mixture or from whole-cell lysate (Figure 3C, Step 1). Cleavage of SUMOylated proteins with the LysC protease will produce predictable branched peptides as a result of the substitution mutation in SUMO-X at position $82(\mathrm{~T} 82 \mathrm{~K})$ in combination with the lysine residues contained in SUMO-substrates. The substitution of valine and glutamine amino acid residues in SUMO-3 with cysteine residues at positions 85 and 87 in SUMO-X (V85C and Q87C) creates a unique second affinity-tag for use with thiopropyl sepharose beads (Figure 3C, Step 2). This second enrichment step will allow immobilization of the desired SUMOylated peptides from a complex mixture. The site-directed mutation in SUMO-X at position 90 (T90K) produces a unique Trypsin cleavage site and leaves the diglycyl lysine tag intact on the SUMOylated peptides. The resulting modified peptides will then be detected using a mass spectrometry-based approach. The SUMO-X reagent is adaptable to expression using viral vectors for subsequent transduction of primary cultures of hepatocytes, as well as for mouse model systems using tail vein injection methods for delivery and isolation of the SUMO-X-labeled substrate proteins in vivo.

This novel experimental approach should overcome the observed low stoichiometry of SUMOylated substrates within cells, and will likely provide a non-biased molecular tool for identification of novel signal-mediated SUMO-3 substrates. When coupled with a proteomic approach, this 2-step enrichment strategy has previously been used to identify susbstrates and non-consensus SUMO-1 sites in cells [52]. As a proof-of-concept, we show here that 
Ubc9 increases SUMOylation of PXR by SUMO-3 in transfected HeLa cells. Interestingly, over-expression of E3-SUMO-ligase family members PIAS1 and PIAS4 also increases SUMOylated form of PXR in cultured HeLa cells (Figure 3D, compare left panel and middle panel).

When SUMO-X is substituted for SUMO-3, we observe a similar result (Figure 3D, right panel). A close examination of the SUMO-modified form of PXR reveals that PIAS4 functions as a more effective E3 ligase enzyme when compared with PIAS1. Moreover, Ubc9, PIAS1, and PIAS4 can increase SUMO-modified forms of PXR independently. Finally, we note that SUMO-X does not appear to support chain formation on PXR as efficiently as wild-type SUMO-3, with the SUMO-X construct supporting mainly two primary sites of modification (Figure 3, note asterisks). This is highly reminiscent of NR PPAR $\gamma$ that also has two primary sites for SUMOylation (K77 and K365). It is interesting to note that only one of the SUMOylation sites (K365) serves as the functional link between ligand-activated PPAR $\gamma$ and its ability to transrepress NF-kB activity [43].

\section{Acetylation of PXR}

Recent evidence suggests that down-regulation of P300-induced farnesoid-x-receptor (FXR, NR1H4) acetylation alters expression of FXR-target genes involved in lipoprotein and glucose metabolism [53]. A more recent follow-up study indicates that FXR is a target of silent mating type information regulation 2 homolog-SIRT1, a protein deacetylase that mediates nutritional and hormonal modulation of hepatic energy metabolism. The lysine residue in FXR at position 217 (K217) is the major acetylation site targeted by p300 and SIRT1. Acetylation of FXR increases its stability but inhibits heterodimerization with RXR $\alpha$, DNA binding, and transactivation activity [54]. By analogy, PXR is also the likely target of acetylation, however, the extent to which PXR is targeted by SIRT1 or p300 is currently unknown. An experimental approach using 6X-histidine-tagged human PXR coupled with western-blotting analysis utilizing antibodies that recognize acetyl-lysine has been recently developed (Figure 4A). Acetylation of PXR is readily detected using this experimental approach (Figure 4B). These recently published data strongly suggests that PXR is acetylated at some level [55]. The effect of PXR acetylation and metabolic status on ligand-mediated PXR gene activation pathways is currently not well characterized. Interestingly, decreased capacity for drug metabolism is observed in patients with morbid obesity, hepatic steatosis, and non-alcoholic steatohepatitis [56-58]. Future research efforts should seek to determine the extent to which acetylation of PXR is involved in crosstalk between drug metabolism and energy metabolism.

\section{Conclusions}

PXR was originally characterized as a regulator of the homeostatic control of steroids, bile acid, and xenobiotics. However recent evidence has revealed a negative regulatory role for PXR in gluconeogenesis, lipid metabolism, and inflammation through either direct regulation or signal-activated crosstalk with other transcription factors. Ligand binding is the primary mode of PXR activation, but several signaling pathways also interface with PXR and affect its overall responsiveness to environmental stimuli, likely by altering the posttranslational modification status of PXR and subsequent interaction with its associated protein partners. The extent to which competitive post-translational modifications of PXR at individual lysine residues by SUMO-, Acetyl-, and ubiquitin-modification is strongly suspected; however, the data are just beginning to emerge.

Crosstalk between phosphorylation, SUMOylation, ubiquitination or acetylation has been demonstrated in studies of other transcriptional regulators including NFאB and p53 [59, 60], and this area needs to be further explored with respect to post-translational modification of 
PXR. Moreover, virtually nothing is known about the signal- or cell-type-dependent regulation of the machinery involved in generating these post-translational modifications with respect to PXR. It is well known that various cellular stresses including heat shock, osmotic stress, and reactive oxygen species can globally affect SUMO conjugation and deconjugation where examined using a proteomic approach [61-63]. Whether specific changes in post-translational modification of PXR also occurs in response to metabolic, pathogenic, and xenobiotic stress associated with diseases and infection remains an interesting future issue to be explored. Finally, pharmacological manipulation of the complex network of factors that contribute to PXR activity present therapeutic opportunities in the treatment of numerous diseases including lipid and inflammatory disorders.

\author{
Abbreviations \\ PXR Pregnane $\mathrm{x}$ receptor \\ NR nuclear receptor \\ PCN pregnenalone 16 $\alpha$-carbonitrile \\ Rif rifampicin \\ G6Pase glucose-6-phosphatase \\ PEPCK phosphoenolpyruvate carboxykinase \\ CYP3A cytochrome P450 3A \\ CREs cyclic AMP response elements \\ PKA cyclic AMP-dependent protein kinase \\ PGC-1 $\alpha$ peroxisome proliferator-activated receptor gamma coactivator 1-alpha \\ HNF-4a hepatocytes nuclear factor $4 \alpha$ \\ NF-кB nuclear transcription factor kappa B \\ TNFa tumor necrosis factor $\alpha$ \\ Cdk2 cyclin-dependent kinase 2 \\ FXR farnesoid-x-receptor \\ SIRT1 silent mating type information regulation 2 homolog-1 \\ PPAR peroxisome proliferator antigen receptor \\ LXR liver $x$ receptor \\ FOXO1 Forkhead box protein O1 \\ FOXA2 Forkhead box A2
}

\title{
References Cited
}

1. Kliewer SA, Moore JT, Wade L, Staudinger JL, Watson MA, Jones SA, McKee DD, Oliver BB, Willson TM, Zetterstrom RH, Perlmann T, Lehmann JM. An orphan nuclear receptor activated by pregnanes defines a novel steroid signaling pathway. Cell. 1998; 92:73-82. [PubMed: 9489701]

2. Goodwin B, Hodgson E, Liddle C. The orphan human pregnane X receptor mediates the transcriptional activation of CYP3A4 by rifampicin through a distal enhancer module. Mol Pharmacol. 1999; 56:1329-1339. [PubMed: 10570062]

3. Lehmann JM, McKee DD, Watson MA, Willson TM, Moore JT, Kliewer SA. The human orphan nuclear receptor PXR is activated by compounds that regulate CYP3A4 gene expression and cause drug interactions. J Clin Invest. 1998; 102:1016-1023. [PubMed: 9727070] 
4. Blumberg B, Sabbagh W Jr, Juguilon H, Bolado J Jr, van Meter CM, Ong ES, Evans RM. SXR, a novel steroid and xenobiotic-sensing nuclear receptor. Genes Dev. 1998; 12:3195-3205. [PubMed: 9784494]

5. Jones SA, Moore LB, Shenk JL, Wisely GB, Hamilton GA, McKee DD, Tomkinson NC, LeCluyse EL, Lambert MH, Willson TM, Kliewer SA, Moore JT. The pregnane X receptor: a promiscuous xenobiotic receptor that has diverged during evolution. Mol Endocrinol. 2000; 14:27-39. [PubMed: 10628745]

6. Moore LB, Maglich JM, McKee DD, Wisely B, Willson TM, Kliewer SA, Lambert MH, Moore JT. Pregnane $\mathrm{X}$ receptor (PXR), constitutive androstane receptor (CAR), and benzoate $\mathrm{X}$ receptor (BXR) define three pharmacologically distinct classes of nuclear receptors. Mol Endocrinol. 2002; 16:977-986. [PubMed: 11981033]

7. Maglich JM, Stoltz CM, Goodwin B, Hawkins-Brown D, Moore JT, Kliewer SA. Nuclear pregnane $\mathrm{x}$ receptor and constitutive androstane receptor regulate overlapping but distinct sets of genes involved in xenobiotic detoxification. Mol Pharmacol. 2002; 62:638-646. [PubMed: 12181440]

8. Rosenfeld JM, Vargas R Jr, Xie W, Evans RM. Genetic profiling defines the xenobiotic gene network controlled by the nuclear receptor pregnane X receptor. Mol Endocrinol. 2003; 17:12681282. [PubMed: 12663745]

9. Dunn RT 2nd, Gleason BA, Hartley DP, Klaassen CD. Postnatal ontogeny and hormonal regulation of sulfotransferase SULT1B1 in male and female rats. J Pharmacol Exp Ther. 1999; 290:319-324. [PubMed: 10381794]

10. Falkner KC, Pinaire JA, Xiao GH, Geoghegan TE, Prough RA. Regulation of the rat glutathione Stransferase A2 gene by glucocorticoids: involvement of both the glucocorticoid and pregnane $\mathrm{X}$ receptors. Mol Pharmacol. 2001; 60:611-619. [PubMed: 11502894]

11. Runge-Morris M, Wu W, Kocarek TA. Regulation of rat hepatic hydroxysteroid sulfotransferase (SULT2-40/41) gene expression by glucocorticoids: evidence for a dual mechanism of transcriptional control. Mol Pharmacol. 1999; 56:1198-1206. [PubMed: 10570047]

12. Sonoda J, Xie W, Rosenfeld JM, Barwick JL, Guzelian PS, Evans RM. Regulation of a xenobiotic sulfonation cascade by nuclear pregnane X receptor (PXR). Proc Natl Acad Sci U S A. 2002; 99:13801-13806. [PubMed: 12370413]

13. Xu C, Wang X, Staudinger JL. Regulation of tissue-specific carboxylesterase expression by pregnane $x$ receptor and constitutive androstane receptor. Drug Metab Dispos. 2009; 37:15391547. [PubMed: 19359405]

14. Geick A, Eichelbaum M, Burk O. Nuclear receptor response elements mediate induction of intestinal MDR1 by rifampin. J Biol Chem. 2001; 276:14581-14587. [PubMed: 11297522]

15. Kast HR, Goodwin B, Tarr PT, Jones SA, Anisfeld AM, Stoltz CM, Tontonoz P, Kliewer S, Willson TM, Edwards PA. Regulation of multidrug resistance-associated protein 2 (ABCC2) by the nuclear receptors pregnane $\mathrm{X}$ receptor, farnesoid $\mathrm{X}$-activated receptor, and constitutive androstane receptor. J Biol Chem. 2002; 277:2908-2915. [PubMed: 11706036]

16. Staudinger J, Liu Y, Madan A, Habeebu S, Klaassen CD. Coordinate regulation of xenobiotic and bile acid homeostasis by pregnane X receptor. Drug Metab Dispos. 2001; 29:1467-1472. [PubMed: 11602523]

17. Argaud D, Halimi S, Catelloni F, Leverve XM. Inhibition of gluconeogenesis in isolated rat hepatocytes after chronic treatment with phenobarbital. Biochem J. 1991; 280 (Pt 3):663-669. [PubMed: 1764030]

18. Bhalla S, Ozalp C, Fang S, Xiang L, Kemper JK. Ligand-activated pregnane X receptor interferes with HNF-4 signaling by targeting a common coactivator PGC-1alpha. Functional implications in hepatic cholesterol and glucose metabolism. J Biol Chem. 2004; 279:45139-45147. [PubMed: 15322103]

19. Kodama S, Moore R, Yamamoto Y, Negishi M. Human nuclear pregnane X receptor cross-talk with CREB to repress cAMP activation of the glucose-6-phosphatase gene. Biochem J. 2007; 407:373-381. [PubMed: 17635106]

20. Zhou J, Zhai Y, Mu Y, Gong H, Uppal H, Toma D, Ren S, Evans RM, Xie W. A novel pregnane X receptor-mediated and sterol regulatory element-binding protein-independent lipogenic pathway. $\mathrm{J}$ Biol Chem. 2006; 281:15013-15020. [PubMed: 16556603] 
21. Matsuzaki H, Daitoku H, Hatta M, Tanaka K, Fukamizu A. Insulin-induced phosphorylation of FKHR (Foxo1) targets to proteasomal degradation. Proc Natl Acad Sci U S A. 2003; 100:1128511290. [PubMed: 13679577]

22. Nakae J, Kitamura T, Silver DL, Accili D. The forkhead transcription factor Foxo1 (Fkhr) confers insulin sensitivity onto glucose-6-phosphatase expression. J Clin Invest. 2001; 108:1359-1367. [PubMed: 11696581]

23. Fan W, Yanase T, Morinaga H, Okabe T, Nomura M, Daitoku H, Fukamizu A, Kato S, Takayanagi $\mathrm{R}$, Nawata $\mathrm{H}$. Insulin-like growth factor 1/insulin signaling activates androgen signaling through direct interactions of Foxo1 with androgen receptor. J Biol Chem. 2007; 282:7329-7338. [PubMed: 17202144]

24. Zhao HH, Herrera RE, Coronado-Heinsohn E, Yang MC, Ludes-Meyers JH, Seybold-Tilson KJ, Nawaz Z, Yee D, Barr FG, Diab SG, Brown PH, Fuqua SA, Osborne CK. Forkhead homologue in rhabdomyosarcoma functions as a bifunctional nuclear receptor-interacting protein with both coactivator and corepressor functions. J Biol Chem. 2001; 276:27907-27912. [PubMed: 11353774]

25. Kodama S, Koike C, Negishi M, Yamamoto Y. Nuclear receptors CAR and PXR cross talk with FOXO1 to regulate genes that encode drug-metabolizing and gluconeogenic enzymes. Mol Cell Biol. 2004; 24:7931-7940. [PubMed: 15340055]

26. Grieco A, Forgione A, Miele L, Vero V, Greco AV, Gasbarrini A, Gasbarrini G. Fatty liver and drugs. Eur Rev Med Pharmacol Sci. 2005; 9:261-263. [PubMed: 16237810]

27. Morere P, Nouvet G, Stain JP, Paillot B, Metayer J, Hemet J. Information obtained by liver biopsy in 100 tuberculous patients. Sem Hop. 1975; 51:2095-2102. [PubMed: 170685]

28. Puigserver P, Rhee J, Donovan J, Walkey CJ, Yoon JC, Oriente F, Kitamura Y, Altomonte J, Dong $\mathrm{H}$, Accili D, Spiegelman BM. Insulin-regulated hepatic gluconeogenesis through FOXO1PGC-1alpha interaction. Nature. 2003; 423:550-555. [PubMed: 12754525]

29. Wolfrum C, Besser D, Luca E, Stoffel M. Insulin regulates the activity of forkhead transcription factor Hnf-3beta/Foxa-2 by Akt-mediated phosphorylation and nuclear/cytosolic localization. Proc Natl Acad Sci U S A. 2003; 100:11624-11629. [PubMed: 14500912]

30. Nakamura K, Moore R, Negishi M, Sueyoshi T. Nuclear pregnane X receptor cross-talk with FoxA2 to mediate drug-induced regulation of lipid metabolism in fasting mouse liver. J Biol Chem. 2007; 282:9768-9776. [PubMed: 17267396]

31. Louet JF, Hayhurst G, Gonzalez FJ, Girard J, Decaux JF. The coactivator PGC-1 is involved in the regulation of the liver carnitine palmitoyltransferase I gene expression by cAMP in combination with HNF4 alpha and cAMP-response element-binding protein (CREB). J Biol Chem. 2002; 277:37991-38000. [PubMed: 12107181]

32. Doria G, Agarossi G. Inhibition of the immune response in vitro by rifampicin and derivatives. Scand J Respir Dis Suppl. 1973; 84:23-26. [PubMed: 4522074]

33. Ibrahim MS, Maged ZA, Haron A, Khalil RY, Attallah AM. Antibiotics and immunity: effects of antibiotics on mitogen responsiveness of lymphocytes and interleukin-2 production. Chemioterapia. 1988; 7:369-372. [PubMed: 3265360]

34. Paunescu E. In vivo and in vitro suppression of humoral and cellular immunological response by rifampicin. Nature. 1970; 228:1188-1190. [PubMed: 5487244]

35. Xie W, Tian Y. Xenobiotic receptor meets NF-kappaB, a collision in the small bowel. Cell Metab. 2006; 4:177-178. [PubMed: 16950133]

36. Zhou C, Tabb MM, Nelson EL, Grun F, Verma S, Sadatrafiei A, Lin M, Mallick S, Forman BM, Thummel KE, Blumberg B. Mutual repression between steroid and xenobiotic receptor and NFkappaB signaling pathways links xenobiotic metabolism and inflammation. J Clin Invest. 2006; 116:2280-2289. [PubMed: 16841097]

37. Gu X, Ke S, Liu D, Sheng T, Thomas PE, Rabson AB, Gallo MA, Xie W, Tian Y. Role of NFkappaB in regulation of PXR-mediated gene expression: a mechanism for the suppression of cytochrome P-450 3A4 by proinflammatory agents. J Biol Chem. 2006; 281:17882-17889. [PubMed: 16608838]

38. Hu G, Xu C, Staudinger JL. Pregnane X Receptor Is SUMOylated to Repress the Inflammatory Response. J Pharmacol Exp Ther. 2010; 335:342-350. [PubMed: 20719936] 
39. Lonard DM, O'Malley BW. Chapter 4 emerging roles of the ubiquitin proteasome system in nuclear hormone receptor signaling. Prog Mol Biol Transl Sci. 2009; 87:117-135. [PubMed: 20374703]

40. Masuyama H, Hiramatsu Y, Kunitomi M, Kudo T, MacDonald PN. Endocrine disrupting chemicals, phthalic acid and nonylphenol, activate Pregnane $\mathrm{X}$ receptor-mediated transcription. Mol Endocrinol. 2000; 14:421-428. [PubMed: 10707959]

41. Masuyama H, Inoshita H, Hiramatsu Y, Kudo T. Ligands have various potential effects on the degradation of pregnane X receptor by proteasome. Endocrinology. 2002; 143:55-61. [PubMed: 11751591]

42. Lee JH, Park SM, Kim OS, Lee CS, Woo JH, Park SJ, Joe EH, Jou I. Differential SUMOylation of LXRalpha and LXRbeta mediates transrepression of STAT1 inflammatory signaling in IFNgamma-stimulated brain astrocytes. Mol Cell. 2009; 35:806-817. [PubMed: 19782030]

43. Pascual G, Fong AL, Ogawa S, Gamliel A, Li AC, Perissi V, Rose DW, Willson TM, Rosenfeld MG, Glass CK. A SUMOylation-dependent pathway mediates transrepression of inflammatory response genes by PPAR-gamma. Nature. 2005; 437:759-763. [PubMed: 16127449]

44. Zelcer N, Tontonoz P. SUMOylation and PPARgamma: wrestling with inflammatory signaling. Cell Metab. 2005; 2:273-275. [PubMed: 16271524]

45. Staudinger JL, Lichti K. Cell signaling and nuclear receptors: new opportunities for molecular pharmaceuticals in liver disease. Mol Pharm. 2008; 5:17-34. [PubMed: 18159925]

46. Ding X, Staudinger JL. Induction of drug metabolism by forskolin: the role of the pregnane X receptor and the protein kinase a signal transduction pathway. J Pharmacol Exp Ther. 2005; 312:849-856. [PubMed: 15459237]

47. Lichti-Kaiser K, Xu C, Staudinger JL. Cyclic AMP-dependent protein kinase signaling modulates pregnane $\mathrm{x}$ receptor activity in a species-specific manner. J Biol Chem. 2009; 284:6639-6649. [PubMed: 19141612]

48. Ding X, Staudinger JL. Repression of PXR-mediated induction of hepatic CYP3A gene expression by protein kinase C. Biochem Pharmacol. 2005; 69:867-873. [PubMed: 15710363]

49. Pondugula SR, Brimer-Cline C, Wu J, Schuetz EG, Tyagi RK, Chen T. A phosphomimetic mutation at threonine-57 abolishes transactivation activity and alters nuclear localization pattern of human pregnane x receptor. Drug Metab Dispos. 2009; 37:719-730. [PubMed: 19171678]

50. Cheng J, Shah YM, Ma X, Pang X, Tanaka T, Kodama T, Krausz KW, Gonzalez FJ. Therapeutic role of rifaximin in inflammatory bowel disease: clinical implication of human pregnane $\mathrm{X}$ receptor activation. J Pharmacol Exp Ther. 335:32-41. [PubMed: 20627999]

51. Blomster HA, Imanishi SY, Siimes J, Kastu J, Morrice NA, Eriksson JE, Sistonen L. In vivo identification of sumoylation sites by a signature tag and cysteine-targeted affinity purification. $\mathrm{J}$ Biol Chem. 2010; 285:19324-19329. [PubMed: 20388717]

52. Blomster HA, Hietakangas V, Wu J, Kouvonen P, Hautaniemi S, Sistonen L. Novel proteomics strategy brings insight into the prevalence of SUMO-2 target sites. Mol Cell Proteomics. 2009; 8:1382-1390. [PubMed: 19240082]

53. Fang S, Tsang S, Jones R, Ponugoti B, Yoon H, Wu SY, Chiang CM, Willson TM, Kemper JK. The p300 acetylase is critical for ligand-activated farnesoid X receptor (FXR) induction of SHP. J Biol Chem. 2008; 283:35086-35095. [PubMed: 18842595]

54. Kemper JK, Xiao Z, Ponugoti B, Miao J, Fang S, Kanamaluru D, Tsang S, Wu SY, Chiang CM, Veenstra TD. FXR acetylation is normally dynamically regulated by p300 and SIRT1 but constitutively elevated in metabolic disease states. Cell Metab. 2009; 10:392-404. [PubMed: 19883617]

55. Biswas A, Pasquel D, Tyagi RK, Mani S. Acetylation of Pregnane X Receptor protein determines selective function independent of ligand activation. Biochem Biophys Res Commun. 2011

56. Blouin RA, Warren GW. Pharmacokinetic considerations in obesity. J Pharm Sci. 1999; 88:1-7. [PubMed: 9874695]

57. Cheymol G. Effects of obesity on pharmacokinetics implications for drug therapy. Clin Pharmacokinet. 2000; 39:215-231. [PubMed: 11020136] 
58. Fiatarone JR, Coverdale SA, Batey RG, Farrell GC. Non-alcoholic steatohepatitis: impaired antipyrine metabolism and hypertriglyceridaemia may be clues to its pathogenesis. J Gastroenterol Hepatol. 1991; 6:585-590. [PubMed: 1782374]

59. Wu SY, Chiang CM. Crosstalk between sumoylation and acetylation regulates p53-dependent chromatin transcription and DNA binding. EMBO J. 2009; 28:1246-1259. [PubMed: 19339993]

60. Huang TT, Wuerzberger-Davis SM, Wu ZH, Miyamoto S. Sequential modification of NEMO/ IKKgamma by SUMO-1 and ubiquitin mediates NF-kappaB activation by genotoxic stress. Cell. 2003; 115:565-576. [PubMed: 14651848]

61. Flick K, Kaiser P. Proteomic revelation: SUMO changes partners when the heat is on. Sci Signal. 2009; 2:pe45. [PubMed: 19638612]

62. Golebiowski F, Matic I, Tatham MH, Cole C, Yin Y, Nakamura A, Cox J, Barton GJ, Mann M, Hay RT. System-wide changes to SUMO modifications in response to heat shock. Sci Signal. 2009; 2:ra24. [PubMed: 19471022]

63. Bossis G, Melchior F. SUMO: regulating the regulator. Cell Div. 2006; 1:13. [PubMed: 16805918]

64. Tatham MH, Rodriguez MS, Xirodimas DP, Hay RT. Detection of protein SUMOylation in vivo. Nat Protoc. 2009; 4:1363-1371. [PubMed: 19730420] 


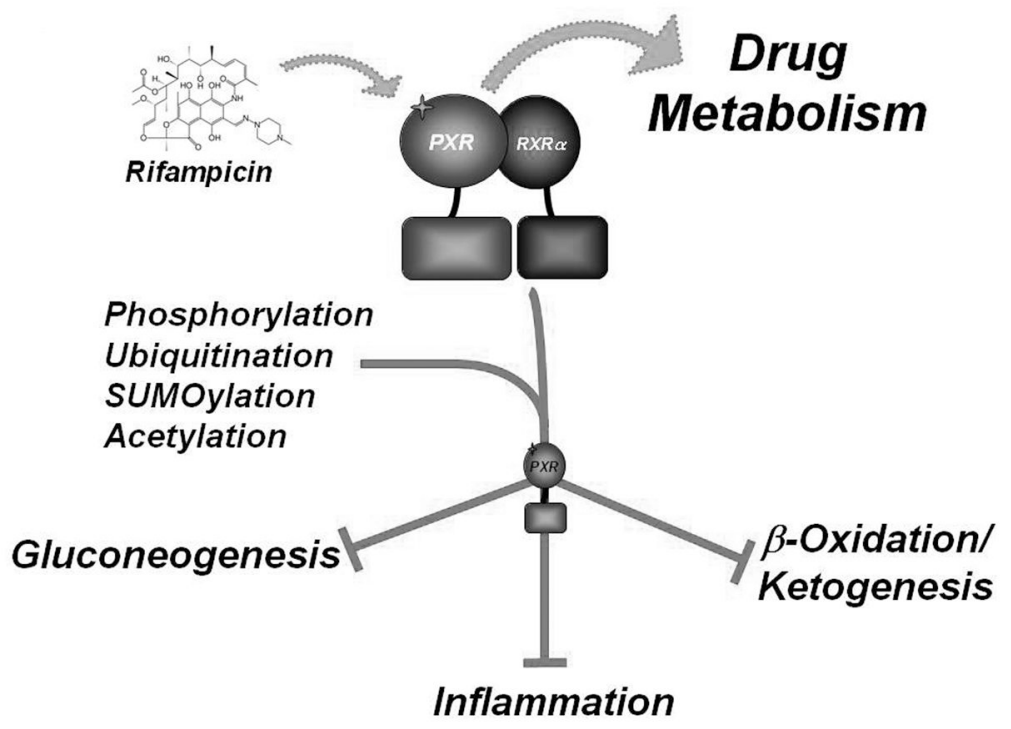

Figure 1. Negative Regulatory Roles of PXR

PXR was originally characterized for its role in xenobiotic and endobiotic detoxification. However, recent evidence has described a role for PXR in glucose and lipid homeostasis, as well as in repression of inflammatory programs of gene expression. A central role for posttranslational modification of PXR is hypothesized to selectively repress biochemical pathways in liver and intestine. 
Figure 2A

\section{X-His-Ub Pull-down}

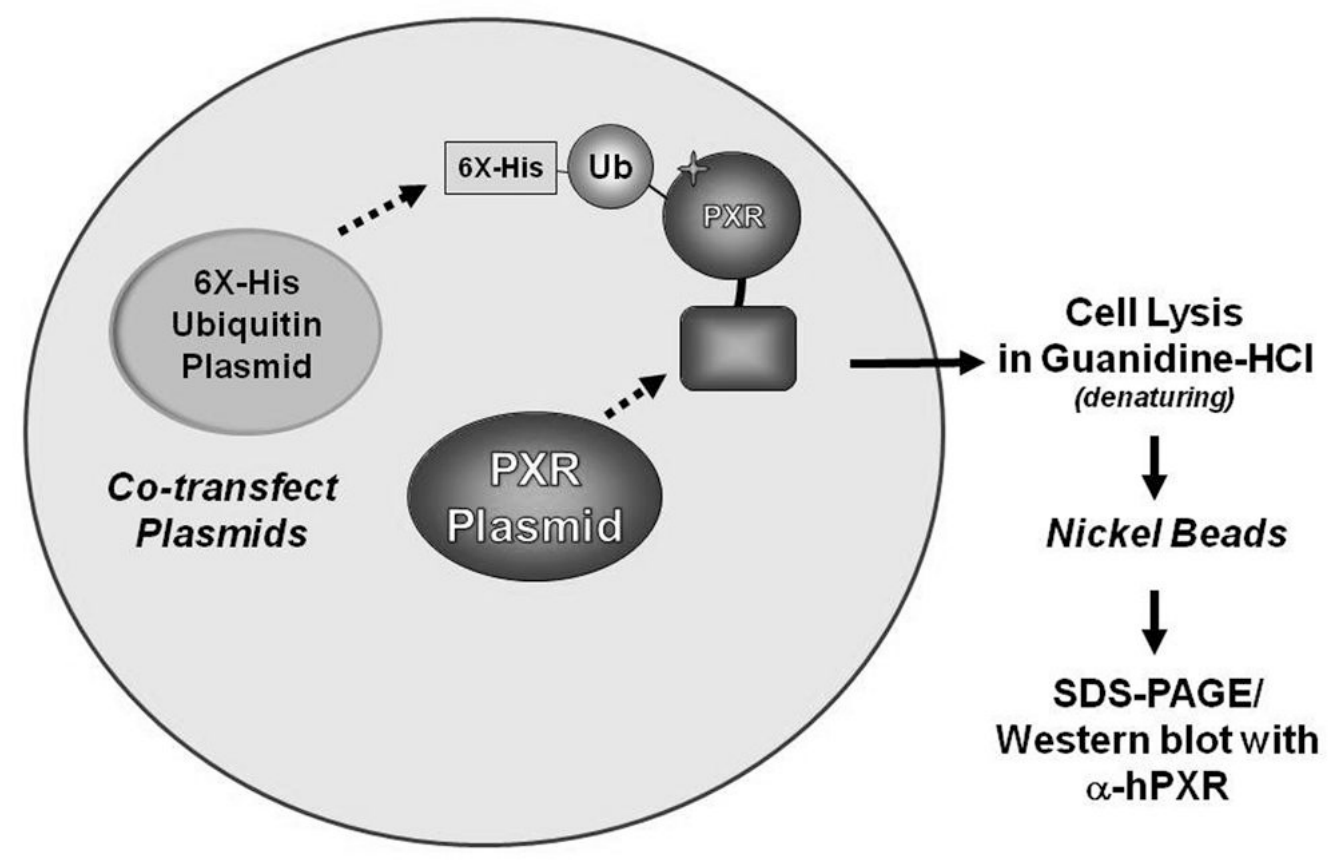

Figure 2B

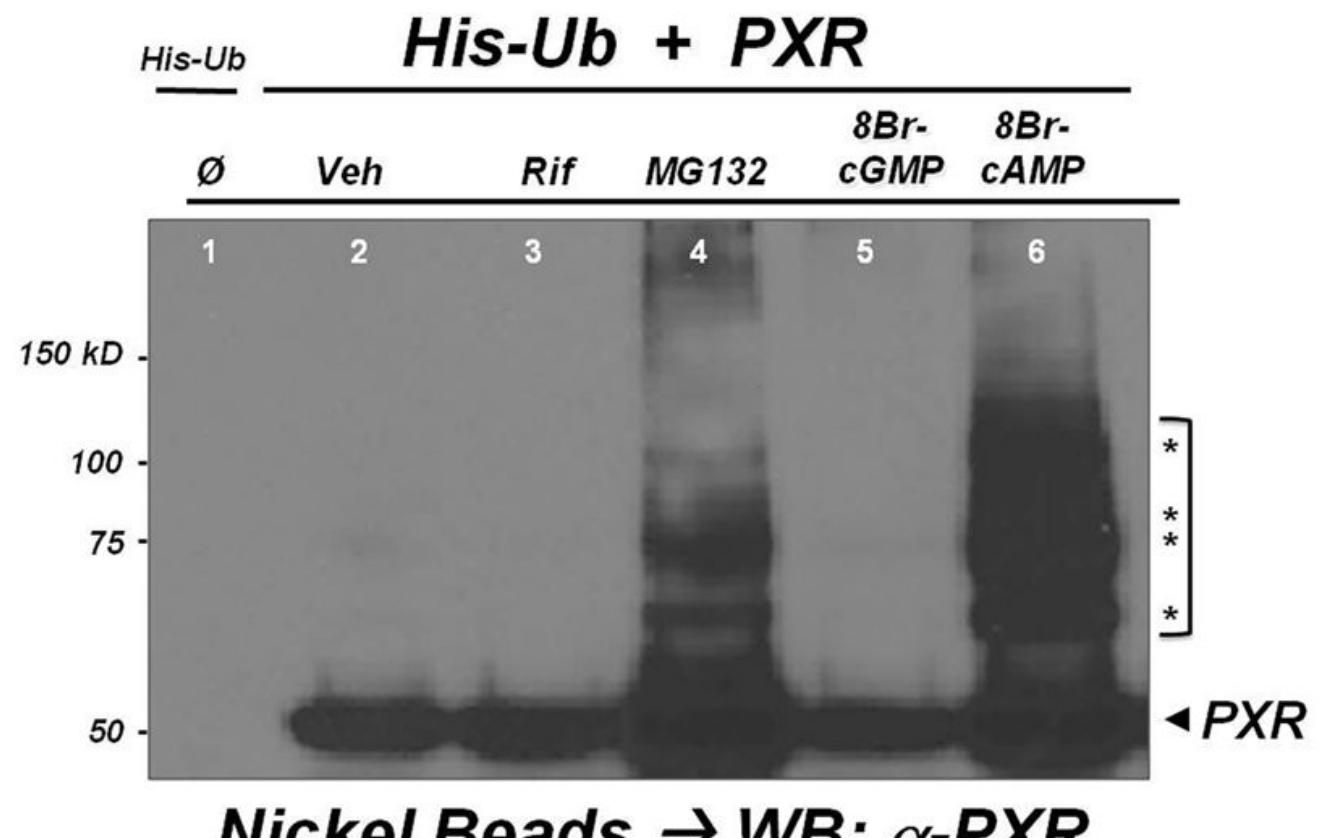

Nickel Beads $\rightarrow$ WB: $\alpha-P X R$ 
Figure 2C

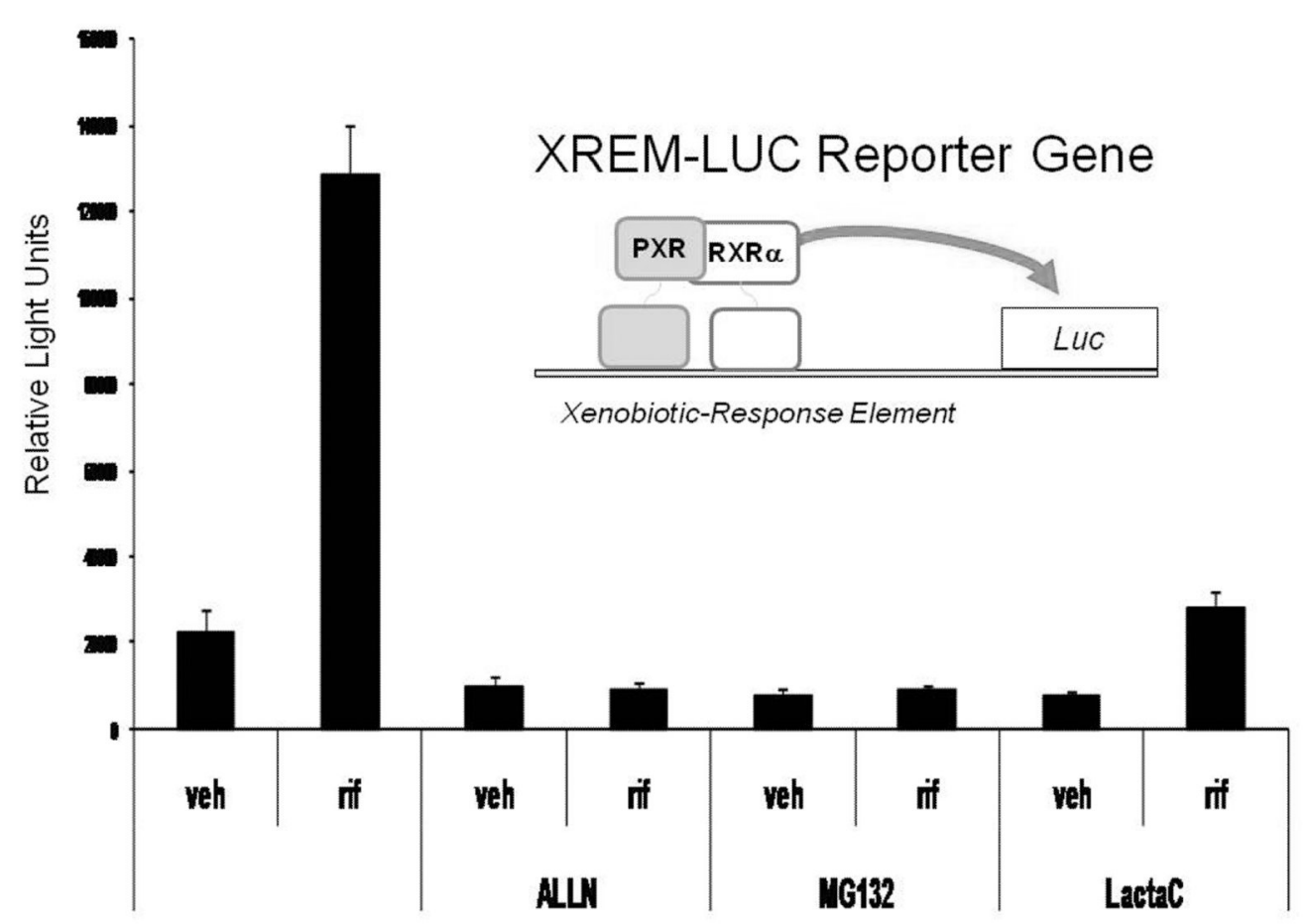

Figure 2. Ubiquitination of PXR

(A) Mammalian expression vectors encoding affinity-tagged (6X-histidine) ubiquitin and human PXR are introduced into cultured HeLa cells using lipofectamine as described [36]. Twenty-four hr post-transfection, cells were treated with Rif $(10 \mu \mathrm{M})$, MG132 $(25 \mu \mathrm{M}), 8$ Bromo cyclic AMP (0.5 mM, 8-Br- cAMP), or 8-bromo cyclicGMP (0.5 mM, 8-Br- cGMP) for an additional $24 \mathrm{hr}$. Whole-cell lysates were generated using denaturing conditions as described [64]. (B) Western blotting was performed using a monoclonal antibody specific for human PXR (sc-48340, Santa Cruz). (C) The PXR-dependent XREM-LUC reporter gene [2] was transfected together with an expression vector encoding human PXR. Twenty-four hr post-transfection, cells were treated with vehicle, Rif (10mM), ALLN (100 $\mu \mathrm{M})$, MG132 $(25 \mu \mathrm{M})$, or lactacystin $(10 \mu \mathrm{M})$ for an additional $24 \mathrm{hr}$. The data are reported as relative light units and represent the mean of assays performed in triplicate $\pm \mathrm{SE}$ and is normalized to $\beta$-galactosidase activity. 


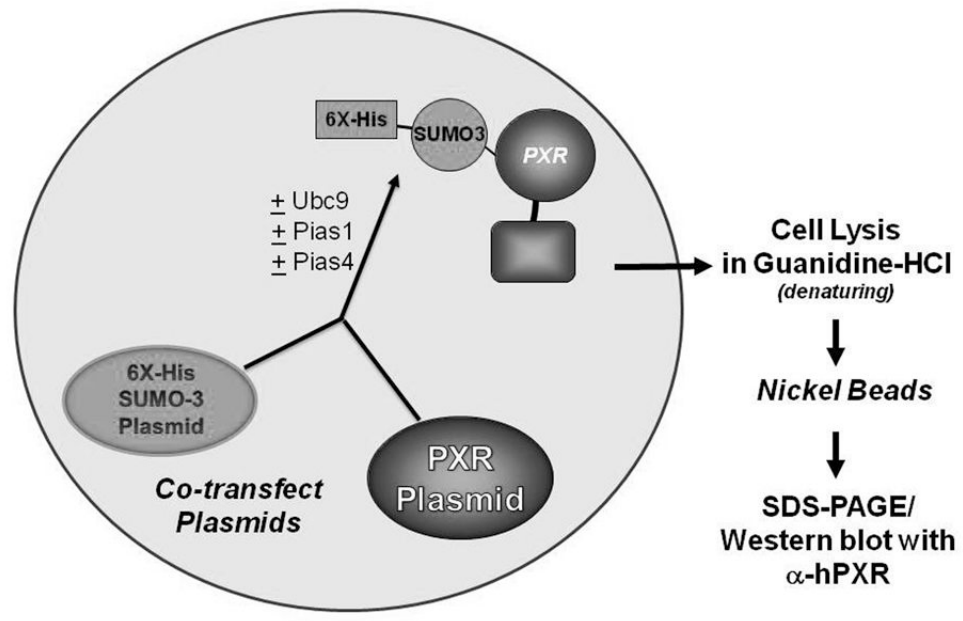

Figure 3B

\section{SUMO-X is an An Engineered Form of SUMO-3}

SUMO-X MSEEKPKEGVKTENDHINLKVAGQDGSVVQFKIKRHTPLSKLMKAYSERQGLSM 54 SUMO-3 MSEEKPKEGVKTENDHINLKVAGQDGSVVQFKIKRHTPLSKLMKAYCERQGLSM 54

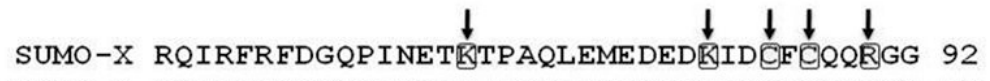
SUMO-3 RQIRFRFDGQPINETDTPAQLEMEDEDTIDVFQQQTGG 92

\section{C47S, D70K, T82K, V85C, Q87C, T90R}

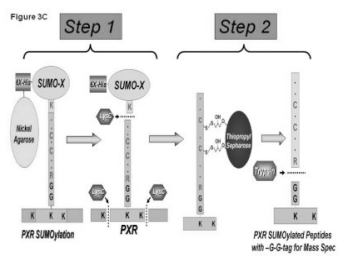


Figure 3D

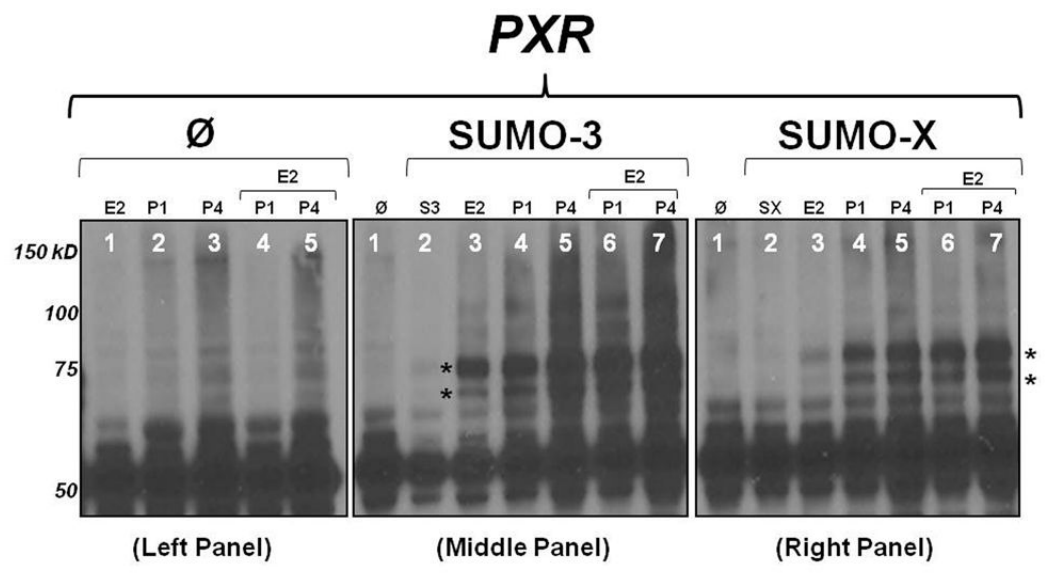

Nickel Beads $\rightarrow$ WB: $\alpha-P X R$ mAb

Figure 3. SUMOylation of PXR

(A) Mammalian expression vectors encoding affinity-tagged (6X-histidine) SUMO-3 and human PXR are introduced into cultured HeLa cells in the presence and absence of E2 ligase (Ubc9), and the E3 ligase enzymes PIAS1, or PIAS4. Forty-eight hr post-transfection, whole-cell lysates were generated as described [64]. (B) The SUMO-X protein incorporates several key point mutations to allow non-biased enrichment and identification of SUMOylated PXR peptides when expressed together with substrates in vitro, in cultured cells, or in live animals. (C) Key altered amino acid residues are colored in RED. Sumotargeted Lysine residues are protected from digestion with LysC protease. The SUMOylated peptide of interest is indicated with GOLD color. STEP 1. The PXR protein is SUMOylated and enriched using Nickel-agarose beads. After washing, LysC cleavage results in the release of the Cysteine tag from the rest of SUMOX. The substrate is also digested, but the SUMOylated Lysine residue is protected from cleavage. STEP 2. Using Thiopropyl sepharose, the SUMOylated cysteine peptides are covalently retained. The target peptides are eluted with trypsin digestion, and the diglycine (GG)-modified target lysine in PXR is identified as a SUMOylation site using LC-MS/MS. (D) The cDNAs encoding HisSUMO-3, His-SUMOX, Ubc9, PIAS1, or PIAS4 were transfected alone or together as indicated. Isolated PXR protein was detected using a monoclonal antibody that recognize human PXR. 
Figure 4A

\section{X-His-PXR Pull-down}

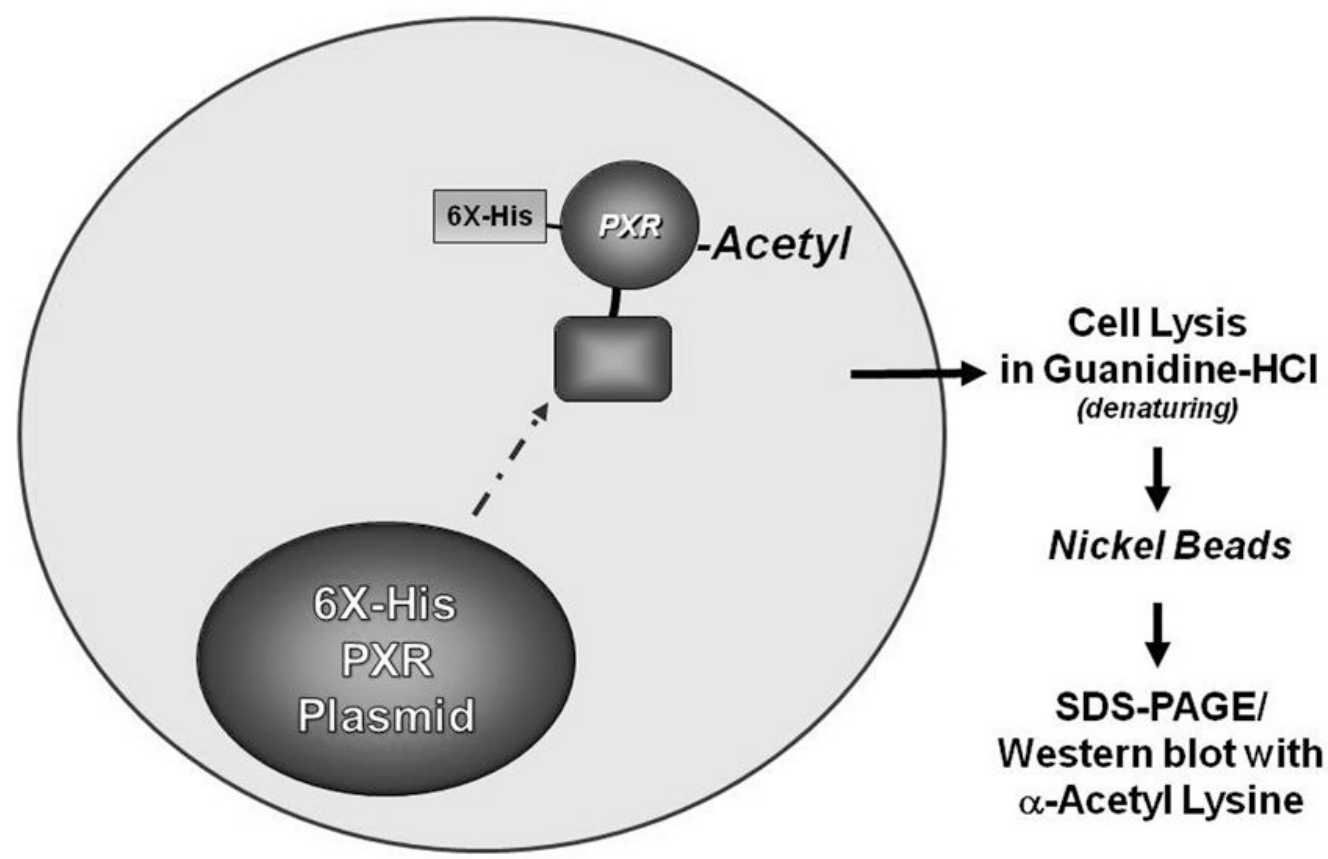

Figure 4B

293T
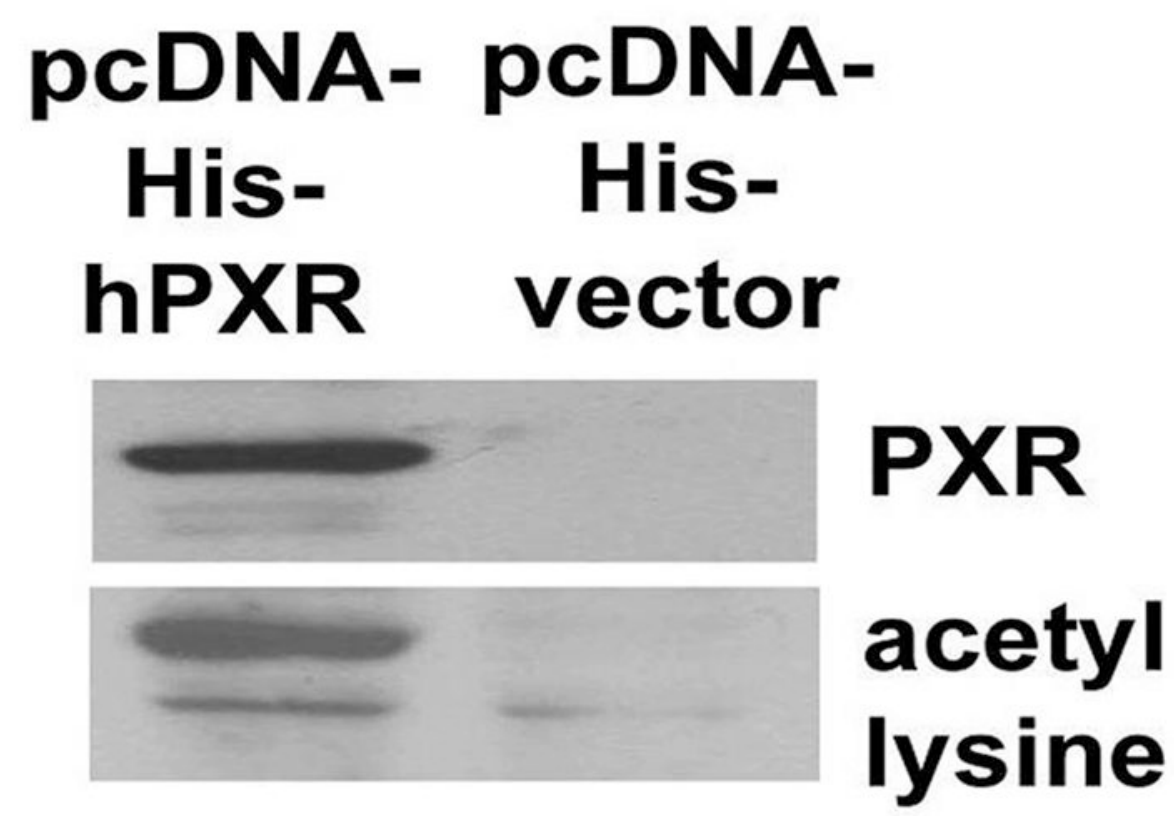

Figure 4. Acetylation of PXR 
(A) Cultured 293T cells are transfected with either a His-tagged human PXR expression construct (pCDNA-His-hPXR) or an empty pCDNA-His vector plasmid as a negative control. (B) Captured proteins from nuclear extracts were subjected to SDS-PAGE and subsequent western blot analysis using an antibody that recognizes either human PXR (Top Panel) or acetyl-lysine (Bottom Panel). 